\title{
Sorption Concentration of Arsenic Ions by Magnetite
}

\author{
Damir Afgatovich Kharlyamov ${ }^{1}$, Pavel Andreevich Katasonov ${ }^{1}$, Gennady Vitalievich Mavrin ${ }^{1}$, Irina Yakovlevna \\ Sippel $^{1} \&$ Munir Nafisovich Miftahov ${ }^{1}$ \\ ${ }^{1}$ Kazan (Volga Region) Federal University Russian Federation, Naberezhnye Chelny, Russia \\ Correspondence: Damir Afgatovich Kharlyamov, Kazan (Volga Region) Federal University Russian Federation, \\ Naberezhnye Chelny, Russia. E-mail: kharlyamov@gmail.com
}

Received: October 26, 2014

Accepted: November 6, $2014 \quad$ Online Published: December 14, 2014

doi:10.5539/mas.v9n3p71

URL: http://dx.doi.org/10.5539/mas.v9n3p71

\begin{abstract}
This paper is focused on the possibility of using magnetite powders obtained by chemical and plasma-chemical method for sorption concentration of arsenic ions. Processes of arsenic concentration by two-site sorption in magnetite-water system have been studied, and the optimal conditions for concentration have been defined. In static mode, effects of $\mathrm{pH}$, temperature and contact time on the adsorption process have been studied. As a result, a method for pre-sorption concentration has been proposed, allowing reducing the lower limit of the atomic absorption determination of arsenic content.
\end{abstract}

Keywords: arsenic, sorption, concentration, magnetite

\section{Introduction}

\subsection{The Problems of Environment Pollution with Arsenic}

The problems of environment pollution with arsenic (As) are recognized and identified in many countries world-wide, in a wide range of climatic and geological conditions. As is a strong toxicant. Its compounds affect all systems in an organism and can cause malignant tumors. At the moment, according to the interim directive of the World Health Organization, allowable concentration of As in drinking water is $10 \mathrm{mg} / \mathrm{l}$, while before 1993 it was $50 \mathrm{mg} / \mathrm{l}$. Most industrialized countries have adopted the value of $10 \mathrm{mg} / \mathrm{l}$ as a legal limit, while most developing countries continue to use the value adopted by the WHO before 1993 as national standard due to difficulties with the analytical detection and compliance with requirements (Arsenic in Groundwater, 2014).

Arsenic is found in all parts of the environment and, being a movable element, it is exposed to various physical and chemical processes. As conditions change, it is oxidized, restored, methylated, volatilized, adsorbed or desorbed. Soil solutions always contain some amount of As, including forms that are available for absorption by plants and biological transformation (Fendorf et al., 2004). Soluble As is also capable of migrating with infiltrating water and becomes a problem at high loads, when the environmental conditions are not favorable for reducing its levels. Mobility and biological availability of As in soils and rocks is controlled by processes of adsorption and desorption (Goldberg et al., 2005; Redman et al., 2002).

Significant amounts of As in the environment are related to natural geological processes, various anthropogenic sources: mining and chemical industry, metallurgy, power stations, use of pesticides. In water and soils, As may be activated by natural processes of aeolation and microbial activity. As mobility can start or increase under the influence of anthropogenic factors (Putilina, 2011).

In natural waters, As is present in organic and inorganic forms in oxidation states ${ }^{+5}$ (arsenate) and ${ }^{+3}$ (arsenite) (Alvarez-Benedi, 2005; Williams, 2003). Elemental As (metal) is rare, and As (-III) exists only with an extremely low redox potential (Arai, 2005). As +3 , As (III) is more agile and many times more toxic than $\mathrm{As}+5$, As (V) (Vodyanitsky 2009; Puzanov, 2009).

\subsection{Methods of as Ions Concentration}

As a result, monitoring of As content in natural waters and other environmental objects in course of studying its biological role and mechanisms of biological transformation is a very important task. In order to quantitatively determine As content, methods of spectrophotometry, stripping voltammetry, and atomic absorption spectroscopy (AAS) are most widely used. However, arsenic detection limits achieved with the help of these methods do not allow solving many analytical problems. In particular, preliminary concentration phase is 
required for performing hydro-chemical studies in course of studying the As biological role and mechanisms of its biological transformation.

Use of concentration makes it possible to reduce sample volume, significantly reduce or eliminate influence of background macro components and increase sensitivity of analysis (Karpov and Savostin, 2003). Several effective methods have been proposed for concentrating As. These include: sedimentation with inorganic and organic reagents, extraction, chromatographic methods, sorption, excreting in the form of volatile arsine, etc. (Zolotov and Kuzmin, 1990; Fazullin et al., 2010).

Among methods of concentration, sorption is the most effective one, making it possible to sorptionally concentrate large volumes of microcomponent from large volumes of solutions on a relatively small mass of sorbent. Sorption is widely used for separating and concentrating substances. Sorption methods usually ensure good separation selectivity, high coefficients of concentration. The highest values of concentration coefficients are achieved in course of determining microcomponents content directly in the sorbent phase using the atomic emission, atomic absorption and X-ray fluorescence methods. Sorption process is relatively easy to manage, since by varying conditions of the experiment, it is possible to perform quantitative sorption-desorption and to monitor this process. Sorption methods do not require complex instrumentation, extreme conditions; they can be easily combined with methods of subsequent components determination. Sorption methods are characterized by high adaptability and ease of automation. It is possible to analyze not only the operation of concentration, but also the definition itself, e.g., in chromatography and flow-injection methods (Mizuike, 1986).

Thiols containing compounds form complexes with As (Yu, 1983), and this property is frequently used for concentration. Authors have described the procedure for As (III) concentration on a thiol-containing fiber. After elution with a solution of hot concentrated hydrochloric acid, As content was determined by means of AAS.

To determine As content in natural water and sodium chloride, a method was used based on formation of an As (III) complex with potassium dipropilditiophosphate followed by its concentrating, by passing the solution through a DIPAX C-16 microcolumn (Malofeeva et al., 1990). Elution was performed using methanol. AAS was performed using $\mathrm{Ni}\left(\mathrm{NO}_{3}\right)_{2}$. A similar approach was also proposed by authors (Pozebo et al., 1998). The As (III) complex with ammonium diethyl dithiophosphate was concentrated by passing the solution through a $\mathrm{C} 18$ microcolumn. Elution was performed into an autosampler container using ethanol. AAS determination was performed using $\mathrm{Pb}\left(\mathrm{NO}_{3}\right)_{2}$.

Author (Howard, 1987) performed selective concentration of As(III) with mercapto-modified silica gel. Concentration was performed in static and dynamic conditions. Elution was performed using hydrochloric acid solution $\mathrm{KIO}_{3}$, after which As content was determined by means of AAS.

A method of determining the total As content in water after preconcentration was proposed by authors (Noriko et al., 1999). The method is based on formation of arsenic molybdate tetrametyl phosphonium, and its subsequent sorption with a membrane filter on the basis of cellulose ethers. After sorption, the membrane was flushed with water and dissolved by heating in a solution of tetramethylammonium hydroxide. AAS determination of As content was performed using a solution of $\mathrm{ZrO}\left(\mathrm{NO}_{3}\right) \cdot 2 \mathrm{H}_{2} \mathrm{O}$ as a modifier.

\subsection{Using Magnetite as a Sorbent}

Sorption capacity of sorbents is largely determined by their specific surface area, which increases with decreasing sorbent particle size. However, this complicates the processes of separating sorbent from the solution using conventional methods of filtration and sedimentation. Therefore, an important objective is to obtain sorbents that along with having good sorption properties could be easily separated from the solution. This problem can be solved if powder of small magnetic particles is used as a sorbent, which can be separated from the solution after adsorbing pollutants under the influence of a gradient magnetic field.

Currently, unique physical properties of ultrafine particles are intensively studied. Such objects that cause interest of researchers are nanoparticles of iron oxide, which may have various composition and type of the crystal lattice. The most common modifications of iron oxide nanoparticles are hematite, maghemite and magnetite $\left(\mathrm{Fe}_{3} \mathrm{O}_{4}\right)$ (Vaseashta et al., 2007). The unique properties of magnetite determine possible areas of its practical application.

Works (Kharlyamov et al., 2014; Gimenez et al., 2007; Petrova et al., 2011; Yuan, 2009) show sorption activity of magnetite particles as compared to salts of heavy metals, As, phenol, nitrates. As of today, there are several methods of water purification from various contaminants using magnetite that acts as sorbent, or is an element embedded in various sorbents. Magnetite is used as an active layer in flow filters, or as a sorbent with further removal of bound particles by means of magnetic separation. Use of magnetite as a sorbent is also known for 
removing oil and oily organic contaminants and oils from wastewater, and for effective cleaning of raw water from bacteria (Lutoev and Smirnov, 2009).

Due to magnetite abundance in nature, a number of simple ways of obtaining it and its sorption capacity, it is advisable to study the possibility of its use for sorption As ions concentration in the analysis of trace amounts.

\section{Method}

\subsection{Obtaining Magnetite}

Magnetite particles obtained in two different ways were used as a sorbent for As ions concentration. In the first case, magnetite was obtained by plasma method from iron-carbon alloys in gas-discharge plasma with electrolytic cathode (Katasonov et al., 2011). The obtained powder was separated from non-magnetic contaminants, washed thoroughly with de-ionized water and dried in a drying oven at $120^{\circ} \mathrm{C}$ until constant weight is obtained. For obtaining magnetite chemically, the method was used that has been proposed by R. Massart (Massart, 1981), where ferriferous chloride and ferric chloride were used at a ratio of 1 to 2 as initial solutions for obtaining magnetite. Sedimentation was performed at optimal temperatures no higher than 25 $30^{\circ} \mathrm{C}$ at one-and-a-half excess of precipitant, ammonia water.

$$
2 \mathrm{FeCl}_{3}+\mathrm{FeCl}_{2}+8 \mathrm{NH}_{4} \mathrm{OH} \rightarrow \mathrm{Fe}_{3} \mathrm{O}_{4}+8 \mathrm{NH}_{4} \mathrm{Cl}+4 \mathrm{H}_{2} \mathrm{O}
$$

The obtained sediment was separated using a permanent magnet, washed repeatedly with de-ionized water until the solution $\mathrm{pH}$ was $7-8$, and then dried at a temperature of $80^{\circ} \mathrm{C}$ until constant weight was obtained.

Structural parameters and phase composition of the obtained powders were studied using X-ray phase analysis $(\mathrm{XRF})$, microscopic studies were made using an electronic microscope. In order to determine the specific surface area of resulting powders, the method of Brunner-Emmett-Teller (BET) was used.

\subsection{Determination of Optimal Sorption Conditions}

In order to select the optimum conditions for concentration sorption, the properties of the magnetite powders obtained in the static, $\mathrm{pH}$ effect, temperature and contact time on As adsorption mode were studied, and the amount of magnetite sorption (a) was determined.

The $\mathrm{pH}$ values at which As was most completely extracted by magnetite were determined experimentally using characteristic curve of sorption power dependent on medium acidity. In order to determine the optimum interval of $\mathrm{pH}$ (pHop) of arsenic sorption, 0.1-1.5 g of magnetite were placed into a series of $25 \mathrm{ml}$ conical flasks along with $25 \mathrm{ml}$ of $\mathrm{As}^{+3}$ ions at concentration $500 \pm 50 \mathrm{~g} / \mathrm{l}, \mathrm{pH}$ value was adjusted to 1.6 to 12.4, flasks were capped and stirred in a shaker for 2 hours at room temperature $\left(20 \pm 5^{\circ} \mathrm{C}\right)$. Next, the filtrate was separated from the sorbent by means of a permanent magnet. Concentration of As ions was determined using AAS. Degree of sorption $(\mathrm{R}, \%)$ was calculated by the formula (1):

$$
R=\frac{C_{0}-C_{1}}{C_{1}} \cdot 100 \% \frac{1}{2},
$$

Value of sorption (a, $\mathrm{mg} / \mathrm{g}$ ) was determined by the formula (2):

$$
a=\frac{\left(C_{0}-C_{1}\right) \cdot V}{m_{c}},
$$

where $\mathrm{C}_{0}$ is initial concentration of As ions, $\mathrm{mg} / \mathrm{l}$;

$\mathrm{C}_{1}$ is concentration of As ions after sorption, $\mathrm{mg} / \mathrm{l}$;

$\mathrm{V}$ is volume of solution, $\mathrm{ml}$;

$\mathrm{m}_{\mathrm{c}}$ is sorbent weight, $\mathrm{g}$.

According to the results of the experiment, dependency diagrams of $\mathrm{R}, \%=\mathrm{f}(\mathrm{pH})$ were made, which were used for determining optimal values of acidity at which As sorption was maximum. The $\mathrm{R}$ value for each point was taken as the average of three independent replicate experiments.

Dependence of sorption degree on time of mixing $(t, \min )$ with sorbents was studied at optimal $\mathrm{pH}$, time was measured in the interval between 5 and 120 minutes. Sorbent weight was $0.1 \mathrm{~g}$ - for the magnetite obtained by chemical sedimentation, $1.5 \mathrm{~g}$ - for the magnetite obtained by plasma method, the volume of test solution was 25 $\mathrm{ml}$, and concentration of As ions was $500 \pm 50 \mathrm{mg} / \mathrm{l}$. When studying the effect of temperature on the extraction degree, it was changed in the range between 20 and $60 \pm 2{ }^{\circ} \mathrm{C}$. At the end of each experiment degree of sorption 
(R) was calculated, and the obtained data were used to build a "degree of sorption-time" characteristic curve, which was used to determine the optimal time (top) required for complete sorption.

For obtaining sorption isotherms, 0.2-1.5 g of magnetite were placed into a series of Erlenmeyer flasks, $25 \mathrm{ml}$ of $\mathrm{As}^{+3}$ ions solution were added with concentration in the between 1 and $100 \mathrm{mg} / \mathrm{l}$, optimal $\mathrm{pH}$ and temperature conditions were created, flasks were capped and mixed in a shaker for $30 \mathrm{~min}$. The solution was then separated from the sorbent using a magnetic separator, and As concentration was determined using AAS. Next, sorption value was calculates $(\mathrm{a}, \mathrm{mg} / \mathrm{g}$ ) by formula (2) and chart was made in coordinates: "sorption rate - initial concentration"

\subsection{Desorption of as Ions}

Weighed quantity of sorbents with adsorbed As sorbents were placed for desorption into Erlenmeyer flasks covered with $1 \mathrm{n}$ solution of sodium hydroxide and stirred for $2 \mathrm{~h}$. Based on the known sorption rate (a), eluent volume $(\mathrm{V})$, weighed quantity of magnetite $(\mathrm{mc})$ and the concentration of desorbed As $(\mathrm{C} 2)$ desorption rate $(\mathrm{d}, \%)$ was calculated:

$$
d=\frac{C_{2} \cdot V}{a \cdot m_{c}} \cdot 100 \%,
$$

\subsection{Sorption Concentration of as Ions Using Magnetite}

In order to test the proposed concentration method, and for As determination, model solutions with a known content of $\mathrm{As}^{+3}$ in the range between 0.5 and $500 \mathrm{mg} / \mathrm{l}$ were prepared, and sorption and desorption were performed using magnetite obtained chemically. Correctness of results was tested by the "added-found" method. Concentration efficiency Ratio (Ce) was calculated by the formula (4):

$$
K_{e}=\frac{C_{2}}{C_{0}},
$$

where $\mathrm{C}_{0}$ is initial concentration of As ions (introduced), $\mu \mathrm{g} / \mathrm{l}$;

$\mathrm{C}_{2}$ is concentration of as ions in concentrate after desorption, $\mu \mathrm{g} / \mathrm{l}$.

Besides model solutions, the method was tested on a real object (snow cover), in the zone of influence of alleged sources of as emission. Snow samples were taken according to the procedure [28], during the period of its maximum accumulation, just before the snow melting period.

Samples of snow cover were transferred into the melt water at room temperature in containers made of chemically resistant polymer material. Melt water was filtered through a "blue ribbon" constant weight filter, onto which was sedimentation was quantitatively transferred.

After the sample preparation, as content was measured in selected samples of show cover melt water. Next, aliquots with the known content of As ions were injected into samples with initial concentration less than $5 \mathrm{~g} / \mathrm{l}$, after which these samples were subjected to concentration with chemically obtained magnetite under optimum conditions. After sorption, magnetite was separated from the solution and placed into 1n sodium hydroxide solution in a smaller volume, stirred for 2 hours, and the content of As ions in the concentrate after desorption was determined.

\section{Results}

According to XRF, the main component of the powder synthesized by plasma method is magnetite with minor inclusions of hematite. The size of the coherent scattering region was $115 \mathrm{~nm}$. For a chemically obtained powder, the main component is magnetite. The average size of magnetite particles collected into $50-100 \mathrm{~nm}$ associates is $20 \mathrm{~nm}$. The specific area of magnetite surface was measured using BET method and was $0.3 \mathrm{~m} 2 / \mathrm{g}$ for the magnetite obtained by plasma method, and $75 \mathrm{~m} 2 / \mathrm{g}$ for the magnetite obtained chemically.

\subsection{Influence of $\mathrm{pH}$ on Sorption of Arsenic Ions}

The $\mathrm{pH}$ values at which as was most completely extracted by magnetite were determined experimentally using characteristic curve of sorption power dependent on medium acidity. The results are shown in Figure 1. The maximum degree of as sorption by the magnetite obtained by chemical sedimentation is observed in the $\mathrm{pH}$ range between 4 and 8 , and it is $94-97 \%$; and for the magnetite obtained by plasma method it is $90-94 \%$ in the $\mathrm{pH}$ range between 4 and 8 . With increasing $\mathrm{pH}$ towards the alkaline medium, sorption efficiency drops sharply. 


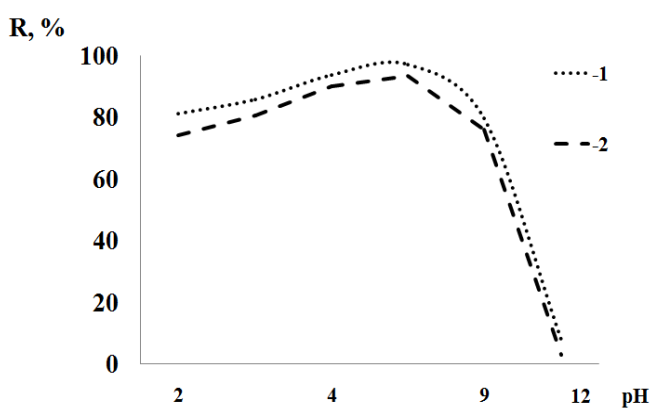

Figure 1. Influence of medium acidity on As sorption by magnetite: 1 - magnetite obtained by chemical sedimentation; 2 - magnetite obtained by plasma method

\subsection{Influence of Time of Contact and Temperature}

The process of as ions sorption by magnetite is strongly influenced by such factors as time and temperature. The rate of elements sorption is of great practical importance, since it greatly determines the time required for the concentration phase. Study of arsenic sorption kinetics shows that magnetite is characterized by relatively high rate of arsenic sorption. Characteristic curves of degree of arsenic ions sorption by the magnetite obtained by chemical sedimentation and plasma-chemical method on the time of phases contact at various temperatures are shown in Figure 2.
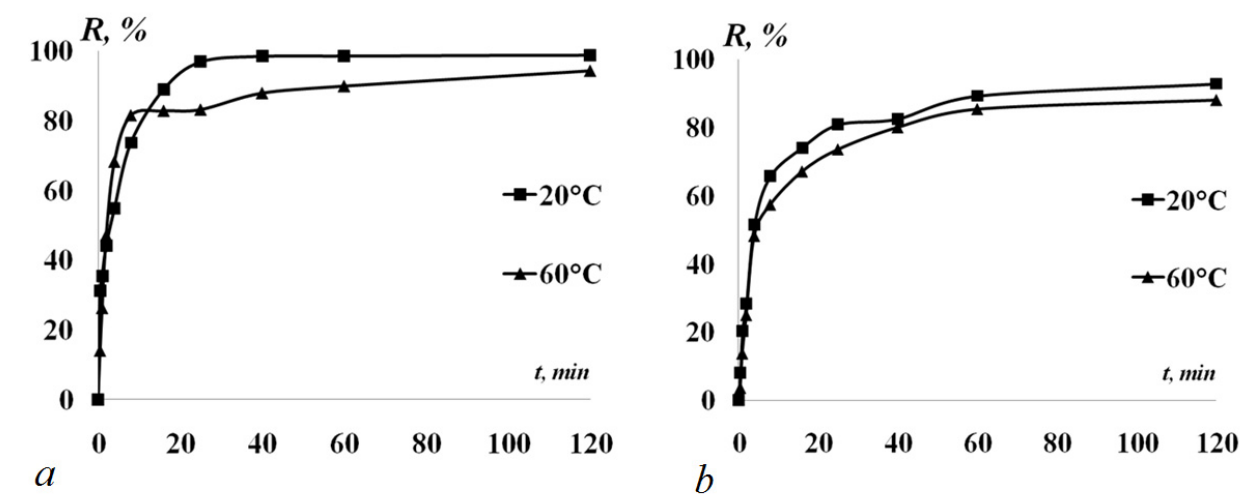

Figure 2. Influence of the mixing time and temperature on As sorption: a - magnetite obtained by chemical sedimentation, $\mathrm{b}$ - magnetite obtained by plasma method

Efficiency of as sorption decreases slightly with increasing temperature. The maximum sorption efficiency for chemically obtained magnetite at $20^{\circ} \mathrm{C}$ was $97 \%$, at $60{ }^{\circ} \mathrm{C}-94 \%$. The maximum sorption efficiency for the magnetite obtained by plasma method at $20{ }^{\circ} \mathrm{C}$ was $93 \%$, at $60{ }^{\circ} \mathrm{C}-88 \%$.

Based on these data, it follows that As ions sorption by the magnetite obtained by plasma process occurs at high rate in the initial time interval; and increasing time of contact does not change adsorption rate by magnetite. The highest rate of as adsorption is observed at $20^{\circ} \mathrm{C}$.

\subsection{Sorption Isotherms}

Figure 3 shows isotherms of As sorption by the magnetite obtained by chemical sedimentation and by plasma-chemical method. According to the obtained data, sorption capacity of the magnetite obtained by chemical sedimentation with respect to the As ions is higher than that of the one obtained by plasma method, which is due to larger surface area of magnetite. 


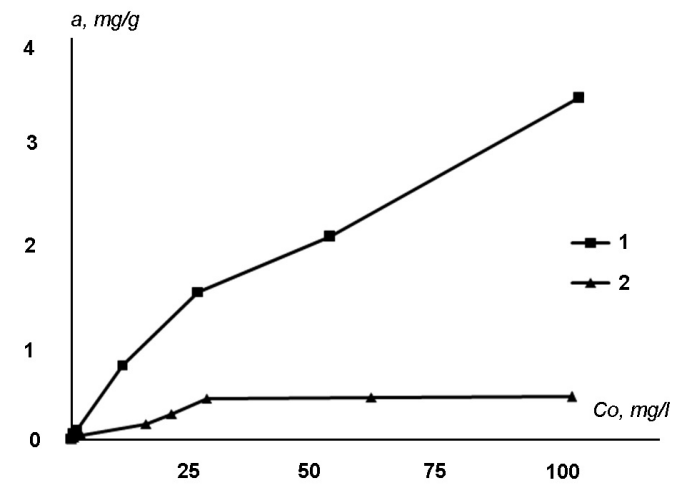

Figure 3. Isotherm of arsenic ions sorption: 1 - magnetite obtained by chemical sedimentation 2 - magnetite obtained by plasma method

Data from the analysis of the isotherms make it possible to state that at saturation point, their projections on the $\mathrm{y}$-axis indicates the value of magnetite sorption capacity. From adsorption isotherms it can be concluded that with increasing concentration, sorption capacity of magnetite in relation to As ions decreases.

\subsection{As Desorption}

Desorption is one of the most important steps in the analysis using sorption-atomic absorption method and makes it possible to reuse sorbent. It has been experimentally established that the quantitative desorption of arsenic ions is achieved by flushing the concentrate with $1 \mathrm{n}$ sodium hydroxide solution for 2 hours. The possibility of quantitative desorption of ions makes it possible to quickly extract sorbed arsenic ions with alkaline solutions, and, in case of the magnetite obtained by plasma method, to reuse it after regeneration (up to 6 cycles).

\subsection{Practical Use of Sorption Concentration}

A possibility has been studied of As concentration and determination in model solutions. Basing on comparison of the obtained data, the magnetite obtained by the CVD method was chosen for practical use, as it makes it possible to more efficiently (sorption degree over 97\%) extract As at $\mathrm{pH} 8.4$ for 25 minutes at $20 \pm 2{ }^{\circ} \mathrm{C}$. Correctness of results was tested by the "added-found" method (table1). Reproducibility of determination is characterized by relative standard deviation $\mathrm{sr}=0.01-0.03$.

Table 1. Correctness of sorption-atomic-absorption As determination in model solutions

\begin{tabular}{lllll}
\hline No. & Injected $(\mathrm{C} 0), \mathrm{mg} / \mathrm{l}$ & Found $(\mathrm{C} 2), \mathrm{mg} / \mathrm{l}$ & $K_{e}$ & $\mathrm{sr}$ \\
\hline 1 & 0.5 & $0.43 \pm 0.22$ & 0.86 & 0.05 \\
2 & 1 & $0.98 \pm 0.49$ & 0.98 & 0.01 \\
3 & 10 & $9.7 \pm 4.9$ & 0.97 & 0.02 \\
4 & 100 & $96 \pm 14.4$ & 0.96 & 0.03 \\
5 & 500 & $489 \pm 73$ & 0.98 & 0.01 \\
\hline
\end{tabular}

In accordance with the obtained results it was established that in case of initially low As content (less than 0.5 $\mathrm{mg} / \mathrm{l}$ ) concentrating efficiency ratio was 0.86 , with increasing concentration from $1 \mathrm{~g} /$ and higher, concentration efficiency value is close to 1 .

For practical use of the proposed method, samples of snow in the zone of influence of the alleged emission sources were taken and analyzed for As content using AAS. In samples where As mass fraction in absolute value was at the lower limit of detection by AAS, experiments were made on As sorption concentration with chemically obtained magnetite. Results are shown in Table 2. 
Table 2. Results of sorption-atomic-absorption As determination in snow cover melt water

\begin{tabular}{|c|c|c|c|}
\hline $\begin{array}{l}\text { No. } \\
\text { point }\end{array}$ & Injected $(\mathrm{C} 0), \mathrm{mg} / \mathrm{l}$ & Found $(\mathrm{C} 2), \mathrm{mg} / \mathrm{l}$ & $\mathrm{sr}$ \\
\hline \multirow[t]{3}{*}{1} & 0 & $2.8 \pm 1.9$ & 0.03 \\
\hline & 10 & $14.5 \pm 7.3$ & 0.02 \\
\hline & 20 & $24.8 \pm 6.2$ & 0.01 \\
\hline \multirow[t]{3}{*}{2} & 0 & $3.3 \pm 1.7$ & 0.02 \\
\hline & 10 & $12.8 \pm 6.4$ & 0.03 \\
\hline & 20 & $23.0 \pm 5.8$ & 0.01 \\
\hline \multirow[t]{3}{*}{3} & 0 & $2.4 \pm 1.2$ & 0.03 \\
\hline & 10 & $12.7 \pm 6.4$ & 0.02 \\
\hline & 20 & $22.8 \pm 5.7$ & 0.01 \\
\hline \multirow[t]{3}{*}{4} & 0 & $3.1 \pm 1.6$ & 0.03 \\
\hline & 10 & $13.4 \pm 6.7$ & 0.01 \\
\hline & 20 & $23.5 \pm 5.9$ & 0.02 \\
\hline \multirow[t]{3}{*}{5} & 0 & $4.6 \pm 2.3$ & 0.03 \\
\hline & 10 & $14.9 \pm 7.5$ & 0.02 \\
\hline & 20 & $24.8 \pm 6.2$ & 0.02 \\
\hline \multirow[t]{3}{*}{6} & 0 & $2.1 \pm 1.1$ & 0.03 \\
\hline & 10 & $12.7 \pm 6.4$ & 0.02 \\
\hline & 20 & $22.6 \pm 5.7$ & 0.01 \\
\hline
\end{tabular}

As it can be seen from the obtained results, the use of concentration made it possible to detect As in samples of snow cover in the zone of influence of alleged sources of As emission, thereby lowering the lower limit of detection with the use of AAS. Thus, studies show perspective of using magnetite for As concentration, and the proposed method can be used for the analysis of natural waters.

\section{Discussion}

As and its compounds are currently regarded as the most dangerous intoxicants, since they have high ability to penetrate into organism. As a result, monitoring of As content in natural waters and other environmental objects in course of studying its biological role and mechanisms of biological transformation is a very important task. Meanwhile, metrological characteristics, such as sensitivity and arsenic detection limit by majority of methods of quantitative chemical analysis, exceed its mass concentration in surface water bodies, which is why there is a need for sample preparation by concentration.

The goal of this work was to study the possibility of reducing concentration detection of arsenic in samples of natural water or precipitation by its concentration with magnetite during the sorption process. Magnetite is proposed as an arsenic sorbent in aqueous solution, which is easily separated from the initial solution due to its paramagnetic properties. Sorption equilibrium has been studied in heterogeneous "magnetite-solutions" systems containing arsenic in the concentration range from sub-micrograms to milligrams per liter of solution.

The optimal conditions for arsenic adsorption that depend on $\mathrm{pH}$, temperature and time of contact have been determined. It has been established that arsenic is almost completely desorbed from magnetite into solution of smaller volume with an available and inexpensive sorbent, which makes it possible to concentrate the solution no less than one order of magnitude.

It has been shown on model solutions that by concentrating arsenic solution one can increase sensitivity of atomic absorption arsenic detection without substantially increasing limits of relative error for drinking and natural water. The method for concentrating arsenic by sorption method using magnetite was successfully applied in atomic-absorption detection of arsenic in melt water from snow cover with submicrogram content of the element.

Based on the obtained data, a method of sample preparation is proposed that consists in preliminary As sorption concentration followed by its determination in the eluate using AAS. The method includes the following stages:

- preparation of samples to ensure transfer of As into mobile cationic form;

- concentrating and recovering As in optimum conditions with the use of magnetite;

- As desorption by flushing sorbent with a solution of alkali of a smaller volume;

- Atomic absorption determination of As ions content in concentrates. 


\section{Conclusion}

During this work, the process of concentrating as by adsorption-desorption in a magnetite-water system was studied. The magnetite powders obtained by chemical and plasma-chemical methods were used as a sorbent for as ions concentration. Desorption was performed with a smaller volume of the solution, resulting in an increase in as content as compared to the original solution. The study of $\mathrm{pH}$, temperature and contact time influence on sorption made it possible to find the optimal conditions for the process of concentration. We also investigated the possibility of using the proposed method for as determination in model solutions and in samples of natural water, where mass fraction of as in absolute values was at the lower limit of detection using AAS. The received results make it possible to consider the magnetite as an effective and low-cost sorbent for extracting as ions in analyzing its trace amounts, for example, in natural water.

\section{References}

Alvarez, B. J. (2005). Adsorption-desorption of arsenate in three Spanish soils. Vadose Zone Journal, 2(4), 282-290. http://dx.doi.org/10.2136/vzj2004.0095

Arai, Y. (2005). Residence time effects on arsenate surface speciation at the aluminum oxide water interface. Soil Science, 5(167), 304-314. http://dx.doi.org/10.1097/00010694-200205000-00001

Arsenic in Groundwater. (2014, June 10). International Groundwater Resources Assessment Centre. Retrieved June 10, 2014, from http://igrac.net/dynamics/modules/SFIL0100/view.php?fil_Id=107

Fazullin, D. D., Mavrin, G. V., \& Melkonyan, R. G. (2014). Removal of Oil Products and Phenol from Waste Water by Composite Sorbents Under Dynamic Conditons. Chemistry and Technology of Fuels and Oils, 50(1), 88-94. http://dx.doi.org/10.1007/s10553-014-0493-5

Fendorf, S., Force, L., M, J., \& Li, G. (2004). Temporal changes in soil partitioning and bioaccessibility of arsenic, chromium, and lead. Journal of Environmental Quality, 1(33), 2049-2055. http://dx.doi.org/10.2134/jeq2004.2049

Gimenez, J., Martinez, M., de Pablo, J., Rovira, M., \& Duro, L. (2007). Arsenic sorption onto natural hematite, magnetite, and goethite. Journal of Hazardous Materials, 121, 575-580. http://dx.doi.org/10.1016/j.jhazmat.2006.07.020

Goldberg, S., Criscenti, L., \& Turner, D. (2005). Adsorption-desorption processes in subsurface reactive transport modeling. Vadose Zone Journal, 3(6), 407-435. http://dx.doi.org/10.2136/vzj2006.0085

Guidelines for assessing the degree of settlements air pollution with metals by their content in snow cover. (2014, June 10). FAOLEX.Retrieved June 10, 2014, Retrieved from http://faolex.fao.org/docs/texts/rus91779.doc

Howard, A. G. (1987). Selective pre-concentration of arsenite on mercapto-modified silica gel. Analyst, 2(112), 159-162. http://dx.doi.org/10.1039/an9871200159

Karpov, Y. A., \& Savostin, A. P. (2003). Methods of sampling and sample preparation. Moscow: BINOM. Knowledge Laboratory.

Katasonov, P. A., Kharlyamov, D. A., Dvoryak, S. V., Garifullin, R. A., Mavrin, G. V., \& Shakirov, I. U. (2011). Arsenic trivelant ions adsorbtion in aqueous solution using spherical synthetic magnetite particles. Scientific and Technical Bulletin of the Volga region, 6, 68-70.

Kharlyamov, D. A., Mavrin, G. V., \& Sippel, I. Y. (2014). About the possibility of sorption concentration of heavy metals using magnetite. Life Science Journal, 8(11), 607-610.

Lutoev, A. A., \& Smirnov, Y. G. (2012). Modeling magnetic properties of iron oxide nanoparticles for treatment systems. Ukhta: The Ukhta State Technical University.

Malofeeva, G. I., Sedykh, E. M., \& Rozhkova, L. S. (1999). Electrothermic atomic absorption determination of stibium and arsenic after concentration by solid-phase extraction. Analytical Chemistry Journal, 2, 162-165.

Massart, R. (1981). Preparation of aqueous magnetic liquids in alkaline and acidic media. IEEE Transactions on Magnetics, 17, 1247-1248. http://dx.doi.org/10.1109/TMAG.1981.1061188

Mizuike, A. (1986). Enrichment Techniques for lnorganic Trace Analysis. Berlin: Springer-Verlag.

Noriko, H., Hiromi, Y., Issei, K., \& Shigeru, T. (1999). Membrane solubilization with tetramethylammonium hydroxide for the preconcentration and electrothermal atomic absorption spectrometric determination of trace amounts of arsenic in water. Analyst, 1(124), 23-26. http://dx.doi.org/ 10.1039/A806856I

Petrova, T., Fachikov, L., \& Hristov, J. (2011). The Magnetite as Adsorbent for Some Hazardous Species from 
Aqueous Solutions: A Review. International Review of Chemical Engineering-Rapid Communications, 2(3), 134-152.

Pozebon, D., Dressier, V. L., Gomes Neto, J. A., \& Curtius, A. J. (1998). Determination of arsenic (III) and arsenic (V) by electrothermal atomic absorption spectrometry after compexation and sorption on a C-18 bonded silica column. Talanta, 45, 1167-1175. http://dx.doi.org/10.1016/S0039-9140(97)00234-8

Putilina, V. S. (2011). Arsenic behavior in soils, rocks and groundwater. Transformation, adsorption/desorption, migration. Novosibirsk: SPSTL of SB RAS.

Puzanov, A. B. (2009). Arsenic in the "Soil-Natural Water-Plants of Altai" system. Soil Science, 9, $1073-1082$.

Redman, A., Macalady, D., \& Ahmann, D. (2002). Natural organic matter affects arsenic speciation and sorption onto hematite. Environmental Science \& Technology, 13(36), 2889-2896. http://dx.doi.org/10.1021/es0112801

Vaseashta, A., Vaclavikovac, M., Vaseashtaa, S., Gallios, G., Roy, P., \& Pum-makarnchana, O. (2007). Nanostructures in environmental pollution detection, monitoring, and remediation. Science and Technology of Advanced Materials, 8, 47-59. http://dx.doi.org/10.1016/j.stam.2006.11.003

Vodyanitsky, Y. N. (2009). Chromium and arsenic in contaminated soils (literature review). Soil Science, 5, 551-559.

Williams, L. E. (2003). Adsorption and transport of Arsenic(V) in experimental subsurface systems. Journal of Environmental Quality, 3(32), 841-850. http://dx.doi.org/10.2134/jeq2003.8410

Yu, M. Q. (1983). Determination of trace arsenic, antimony, selenium and tellurium in various oxidation states in water by hydride generation and atomic-absorption spectrophometry after enrichment and separation with thiol cotton. Talanta, 30(4), 265-270. http://dx.doi.org/10.1016/0039-9140(83)80060-5

Yuan, P. (2009). Montmorillonite-Supported Magnetite Nanoparticles for the Removal of Hexavalent Chromium $[\mathrm{Cr}(\mathrm{VI})]$ from Aqueous Solutions. Journal of Hazardous Materials, 166, 821-829. http://dx.doi.org/10.1016/j.jhazmat.2008.11.083

Zolotov, Y. A., \& Kuzmin, N. M. (1990). Perconcentration of trace elements. Amsterdam: Elsevier.

\section{Copyrights}

Copyright for this article is retained by the author(s), with first publication rights granted to the journal.

This is an open-access article distributed under the terms and conditions of the Creative Commons Attribution license (http://creativecommons.org/licenses/by/3.0/). 